\title{
Immunomodulation in Cutaneous T Cell Lymphoma
}

\author{
Martina Ferranti, Giulia Tadiotto Cicogna, Irene Russo and Mauro Alaibac* \\ Unit of Dermatology, University of Padua, Padua, Italy
}

Keywords: cutaneous T-cell lymphoma, immunosuppression, HIV, CD30 cutaneous T-cell lymphoma, mycosis fungoides

Primary cutaneous lymphomas (PCL), defined as lymphomas limited to the skin with no evidence of extracutaneous disease at the time of diagnosis, are a heterogeneous group of lymphoproliferative disorders. They encompass cutaneous T-cell lymphomas (CTCL) (65\% of all cases), cutaneous B-cell lymphomas (CBCL) (25\% of all cases) and other rarer variants $(1,2)$.

The most common CTCL subtype is mycosis fungoides (MF) which together with Sézary syndrome (SS) accounts for about $65 \%$ of all CTCLs (1). The neoplastic cells of CTCL usually express a CD3+CD4+ mature helper T-cell phenotype. CTCLs include also the group of primary cutaneous CD30+ lymphoproliferative disorders which represent at least 25\% of all CTCLs (1-3). These conditions are generally characterized by expression of the CD30 molecule by more than $75 \%$ of neoplastic lymphocytes. In particular, the group of CD30+ lymphoproliferative disorders of the skin includes two subtypes: lymphomatoid papulosis (LyP) and primary anaplastic large

OPEN ACCESS

Edited by:

Catherine Grace Chung,

The Ohio State University,

United States

Reviewed by:

Brian Poligone,

Rochester General Hospital Research Institute (RGHRI), United States

*Correspondence:

Mauro Alaibac mauro.alaibac@unipd.it

Specialty section

This article was submitted to Hematologic Malignancies, a section of the journal

Frontiers in Oncology

Received: 15 December 2018 Accepted: 23 September 2019 Published: 09 October 2019

Citation:

Ferranti M, Tadiotto Cicogna G,

Russo I and Alaibac M (2019) Immunomodulation in Cutaneous

T Cell Lymphoma.

Front. Oncol. 9:1025.

doi: 10.3389/fonc.2019.01025 cell lymphoma (PALCL) (4). However, these two entities differ significantly in several aspects. In contrast to LyP, PALCL may spread to extracutaneous sites in $10-20 \%$ of the patients, whereas the classical type of LyP is characterized clinically by recurrent self-healing lesions and there is no risk of spread to extracutaneous sites. The presence of clonality by TCR gene rearrangements is detected only in about $40 \%$ LyP cases in contrast to ALCL where it is observed in about $90 \%$ of cases (4). Moreover, in a study investigating the prevalence of PCLs in solid organ transplant recipients it has been demonstrated a significant increase of PALCL in this group of patients whereas only one case of LyP was reported (5). This is consistent with view that LyP is probably a reactive conditions whose onset is hampered by the immunosuppressive therapy, whereas ALCL is a true lymphoma and consequently its development is favored by the immunosuppressive regimen. On the other hand, there are data demonstrating an increased risk of MF in patients with LyP (6). Gene expression analysis in these disorders may help to shed light on this issue.

The role of viral agents in CTCLs is still debated, but it has not possible to date to convincingly establish a causal correlation between a viral infection and CTCL development (7). A recent study investigated CTCLs in HIV-infected and non-HIV-infected patients (8). Data were obtained from the Surveillance, Epidemiology, and End Results program, 1973-2013, of the U.S. National Cancer Institute and showed that HIV-infected patients with CTCL experienced significantly higher survival and a decreased risk of overall mortality than non-HIV-infected patients. Moreover, these results indicated that HIV infection was an independent protective factor. These epidemiological data suggest that a HIV-based therapeutic approach could be appropriate for CTCL. To this regard, previous studies generated a retroviral vector which specifically transfers genes into CD4+ cells by pseudotyping of murine leukemia virus (MLV) capsid particles with a variant of the HIV-1 envelope protein $(9,10)$. These vectors are suitable for gene therapy of CTCL, because they are able to deliver therapeutic genes exclusively to target cells. A subsequent study developed a xenograft mouse model to study CTCL and generated MLV/HIV-pseudotyped vectors encoding the herpes simplex virus thymidine kinase suicide gene (HSV-TK) (11). Vector particles were administered intratumorally into human CTCL xenografts in nude mice which then underwent systemic 
treatment with ganciclovir (GCV). Tumor development was significantly delayed in HSV-TK-transduced and GCV-treated tumors. These data demonstrate that the use of MLV/HIVpseudotyped vectors could be an appropriate approach for the treatment of CTCLs.

Interferons (IFNs) are naturally occurring proteins released by host cells which act as a part of the innate immune response (12). Although IFNs were first identified for their capacity to induce resistance to virus, they also exert a wide range of immunomodulatory and antitumor effects (11). In particular IFN-alpha is an effective treatment for the two main subtypes of CTCL, MF and SS (13). To this regard, IFN alpha promotes the anti-tumor activity of NK cells and CD8+ T lymphocytes (12). However, the efficacy of IFN-alpha is limited by loss of response in a significant proportion of patients. An alternative or adjunctive strategy could be the utilization of the immune checkpoint inhibitors, such as anti-CTLA4 and anti-PD1/PDL1, which have become a new promising way of immunotherapy (14). CTLA4 and PD1 are two immunomodulatory receptors expressed on $\mathrm{T}$ cell and involved in the inhibition of immune system. The interaction between the receptors PD1 and CTLA4 and their ligands (PDL1 and CD80/CD86, respectively) induces a downregulation of $\mathrm{T}$ cell effector functions leading to the inhibition of the antitumor immune response (14). Thus, PD1 inhibitors (nivolumab and pembrolizumab) and CTLA4 inhibitors (ipilimumab) enhance anti-tumor immune response delaying tumor growth and facilitating tumor rejection. The relationship between immune checkpoint inhibitors and CTCL has not yet been clarified. A significant increase of PD1 expression in peripheral blood malignant $\mathrm{T}$ cells has been observed in SS, whereas data regarding overexpression of PD1 and CTLA4 in MF patients are conflicting (15). To this regard, the inhibition of PD1 and CTLA4 may have an important role in controlling the progression of some CTCL and could be investigated as a potential immunotherapy for SS and MF (16). Currently clinical trials over the use of pembrolizumab and

\section{REFERENCES}

1. Willemze R, Jaffe ES, Burg G, Cerroni L, Berti E, Swerdlow SH, et al. WHOEORTC classification for cutaneous lymphomas. Blood. (2005) 105:3768-85. doi: 10.1182/blood-2004-09-3502

2. Swerdlow SH, Campo E, Pileri SA, Harris NL, Stein H, Siebert R, et al. The 2016 revision of the World Health Organization classification of lymphoid neoplasms. Blood. (2016) 127:2375-90. doi: 10.1182/blood-2016-01-643569

3. Maurelli M, Tessari G, Colato C, Schena D, Girolomoni G. Incidence and tenyear follow-up of primary cutaneous lymphomas: a single-centre cohort study. Eur J Dermatol. (2018) 28:44-9.

4. Chen C, Gu YD, Geskin LJ. A review of primary cutaneous CD30+ lymphoproliferative disorders. Hematol Oncol Clin North Am. (2019) 33:121-34. doi: 10.1016/j.hoc.2018.08.003

5. Seçkin D, Barete S, Euvrard S, Francès C, Kanitakis J, Geusau A, et al. Primary cutaneous posttransplant lymphoproliferative disorders in solid organ transplant recipients: a multicenter European case series. Am J Transplant. (2013) 13:2146-53. doi: 10.1111/ajt.12281

6. Cordel N, Tressières B, D'Incan M, Machet L, Grange F, Estève É, et al. (2016) Frequency and risk factors for associated lymphomas nivolumab for the treatment of MF/SS are ongoing $(17,18)$. Promising results in the use of ipilimumab for the treatment of CTCL, specifically SS, have also been observed (19). Interestingly a case of complete regression of MF after ipilimumab therapy for advanced melanoma has been reported (20). On the other hand, a case of cutaneous CD56 + T cell lymphoma that developed during pembrolizumab treatment for metastatic melanoma has been described by Zheng et al. (21). Recently, the approval of mogamulizumab, a humanized defucosylated anti-CC chemokine receptor 4 (CCR4) monoclonal antibody, has expanded the landscape of drugs for the treatment of advanced CTCL (22). CCR4 is expressed in the vast majority of CTCLs, especially when peripheral blood involvement is present. This receptor plays an essential role in T-lymphocyte migration into the skin. In a recent study mogamulizumab significantly improved progression-free survival in advanced CTCL, especially in those with SS which is a subtype of CTCL characterized by peripheral blood involvement (23). Furthermore, a number of clinical trials are currently focusing on evaluating mogamulizumab with checkpoint inhibitors (NCT03309878, NCT02476123) as a means of improving antitumor immunity. For less advanced MF, topical resiquimod gel, a Toll-like receptor $7 / 8$ agonist, has been used (24). This topical approach triggers innate immune responses that in turn support the induction of tumor-specific immunity. Lesions of MF treated with resiquimod gel significantly improved in $75 \%$ of patients and $30 \%$ of patients showed complete resolution of all treated lesions (25). Furthermore, in some patients resiquimod promoted distant response of untreated lesions indicating a systemic antitumor effect of the gel (25).

\section{AUTHOR CONTRIBUTIONS}

MA conceived the idea. MF, GT, IR, and MA contributed to the design of the article and to the writing of the manuscript. in patients with lymphomatoid papulosis. Oncologist 21:76-83. doi: 10.1634/theoncologist.2015-0242

7. Mirvish JJ, Pomerantz RG, Falo LD Jr, Geskin LJ. Role of infectious agents in cutaneous T-cell lymphoma: facts and controversies. Clin Dermatol. (2013) 31:423-31. doi: 10.1016/j.clindermatol.2013.01.009

8. Wang J, Liang R1, Hao C, Liu X, Zhang N, Duan X, et al. Survival outcomes of primary cutaneous T-cell lymphoma in HIV-infected patients: a national population-based study. J Investig Med. (2018) 66:762-7. doi: 10.1136/jim-2017-000636

9. Schnierle BS, Stitz J, Bosch V, Nocken F, Merget-Millitzer H, Engelstädter $\mathrm{M}$, et al. Pseudotyping of murine leukemia virus with the envelope glycoproteins of HIV generates a retroviral vector with specificity of infection for CD4-expressing cells. Proc Natl Acad Sci USA. (1997) 94:8640-5. doi: $10.1073 /$ pnas. 94.16 .8640

10. Thaler S, Schnierle BS. A packaging cell line generating CD4-specific retroviral vectors for efficient gene transfer into primary human T-helper lymphocytes. Mol Ther. (2001) 4:273-9. doi: 10.1006/mthe.2001.0445

11. Thaler S, Burger AM, Schulz T, Schnierle BS. MLV/HIV-pseudotyped vectors: a new treatment option for cutaneous T cell lymphomas. Mol Ther. (2003) 8:756-61. doi: 10.1016/S1525-0016(03)00241-7 
12. Pestka $S$. The interferons: 50 years after their discovery, there is much more to learn. J Biol Chem. (2007) 282:20047-51. doi: 10.1074/jbc.R700004200

13. Spaccarelli N, Rook AH. The use of interferons in the treatment of cutaneous T-cell lymphoma. Dermatol Clin. (2015) 33:731-45. doi: 10.1016/j.det.2015.05.008

14. Sadreddini S, Baradaran B, Aghebati-Maleki A, Sadreddini S, Shanehbandi D, Fotouhi A, et al. Immune checkpoint blockade opens a new way to cancer immunotherapy. J Cell Physiol. (2018) 234:8541-9. doi: 10.1002/jcp.27816

15. Kantekure K, Yang Y, Raghunath P, Schaffer A, Woetmann A, Zhang $\mathrm{Q}$, et al. Expression patterns of the immunosuppressive proteins PD1/CD279 and PD-L1/CD274 at different stages of cutaneous T-cell lymphoma/mycosis fungoides. Am J Dermatopathol. (2012) 34:126-8. doi: 10.1097/DAD.0b013e31821c35cb

16. Alaibac M. Monoclonal antibodies against cutaneous T-cell lymphomas. Expert Opin Biol Ther. (2017) 17:1503-10. doi: 10.1080/ 14712598.2017.1369951

17. Naidoo J, Page DB, Li BT, Connell LC, Schindler K, Lacouture ME, et al. Toxicities of the anti-PD-1 and anti-PD-L1 immune checkpoint antibodies. Ann Oncol. (2015) 26:2375-91. doi: 10.1093/annonc/mdv383

18. Lesokhin AM, Ansell SM, Armand P, Scott EC, Halwani A, Gutierrez M, et al. Nivolumab in patients with relapsed or refractory hematologic malignancy: preliminary results of a phase Ib study. J Clin Oncol. (2016) 34:2698-704. doi: 10.1200/JCO.2015.65.9789

19. Sekulic A, Liang WS, Tembe W, Izatt T, Kruglyak S, Kiefer JA, et al. Personalized treatment of Sézary syndrome by targeting a novel CTLA4:CD28 fusion. Mol Genet Genomic Med. (2015) 3:130-6. doi: 10.1002/mgg3.121

20. Bar-Sela G, Bergman R. Complete regression of mycosis fungoides after ipilimumab therapy for advanced melanoma. JAAD Case Rep. (2015) 1:99-100. doi: 10.1016/j.jdcr.2015.02.009
21. Zheng YJ, Lee A, Pincus L, Ho W, Vujic M, Ortiz-Urda S. Cutaneous CD56+ T-cell lymphoma developing during pembrolizumab treatment for metastatic melanoma. JAAD Case Rep. (2018) 4:540-2. doi: 10.1016/j.jdcr.2018.01.016

22. Ollila TA, Sahin I, Olszewski AJ. Mogamulizumab: a new tool for management of cutaneous T-cell lymphoma. Onco Targets Ther. (2019) 12:1085-94. doi: 10.2147/OTT.S165615

23. Kim YH, Bagot M, Pinter-Brown L, Rook AH, Porcu P, Horwitz $\mathrm{SM}$, et al. Mogamulizumab versus vorinostat in previously treated cutaneous T-cell lymphoma (MAVORIC): an international, open-label, randomised, controlled phase 3 trial. Lancet Oncol. (2018) 19:1192-204. doi: 10.1016/S1470-2045(18)30379-6

24. Killock D. Haematological cancer: resiquimod-a topical CTCL therapy. Nat Rev Clin Oncol. (2015) 12:563. doi: 10.1038/nrclinonc.2015.142

25. Rook AH, Gelfand JM, Wysocka M, Troxel AB, Benoit B, Surber C, et al. Topical resiquimod can induce disease regression and enhance T-cell effector functions in cutaneous T-cell lymphoma. Blood. (2015) 126:1452-61. doi: 10.1182/blood-2015-02-630335

Conflict of Interest: The authors declare that the research was conducted in the absence of any commercial or financial relationships that could be construed as a potential conflict of interest.

Copyright (c) 2019 Ferranti, Tadiotto Cicogna, Russo and Alaibac. This is an openaccess article distributed under the terms of the Creative Commons Attribution License (CC BY). The use, distribution or reproduction in other forums is permitted, provided the original author(s) and the copyright owner(s) are credited and that the original publication in this journal is cited, in accordance with accepted academic practice. No use, distribution or reproduction is permitted which does not comply with these terms. 